\title{
Detection of autoantibodies against heat shock proteins and collapsin response mediator proteins in autoimmune retinopathy
}

\author{
Grazyna Adamus $^{1 *}$, Robert Bonnah ${ }^{1,3}$, Lori Brown ${ }^{1}$ and Larry David ${ }^{2}$
}

\begin{abstract}
Background: Autoimmune retinopathy (AR) and Cancer-Associated Retinopathy (CAR) are associated with a diverse repertoire of anti-retinal autoantibodies (AAbs) but not all antigenic targets have been characterized. Identification of new AAbs may help with clinical diagnosis and prognosis of retinal dysfunction in AR. The goal was to identify frequently targeted retinal autoantigens within the 60-70-kDa molecular weight range.

Methods: Human retinal proteins were separated by SDS-PAGE and 2D gel electrophoresis (2-DE) and sera from AR patients with and without cancer were used to identify immunoreactive proteins by Western blotting. Proteins were identified following separation by electrophoresis, Coomassie staining using in-gel trypsin digestion and mass spectrometric analysis. Circulating serum hsp60 and anti-hsp60 antibody levels were determined by quantitative ELISA.

Results: Retrospective evaluation of 819 patients with anti-retinal AAbs showed that $29 \%$ patients had AAbs targeted proteins between 60-70-kDa. Shotgun mass spectrometry of human retinal proteins present in 1D-gel found 66 species within this range. To identify the immunoreactive proteins, we performed Western blots of 2-DE gels and showed a group of heat shock proteins (hsps), including hsp60 and CRMP proteins that were frequently recognized by AR patient AAbs, irrespective of cancer status. These results were validated by immunostaining of purified hsp60 and CRMP2 proteins. ELISA results revealed that patients with AR and CAR had significantly increased levels of serum anti-hsp60 antibodies compared to control healthy subjects $(p<0.0001)$. However, circulating hsp60 protein was not significantly elevated in sera of either patient group.

Conclusions: Different anti-retinal antibodies frequently co-exist in a single patient, creating antibody-arrays related to the syndrome. Hsps and CRMP-2 are newly identified autoantigens in AR. A frequent co-association of anti-hsp antibodies with other anti-retinal AAbs may augment pathogenic processes, leading to retinal degeneration.
\end{abstract}

Keywords: Autoantibody, Autoimmune retinopathy, CAR, Retina, Autoantigen, Heat shock proteins, CRMP-2

\section{Background}

Retinal degeneration is one of the most common forms of untreatable blindness and can result from many causes, both genetic and acquired. Autoimmunity is increasingly recognized as possible underlying cause of retinal degeneration in autoimmune retinopathies (AR), including paraneoplastic syndromes, such as cancerassociated retinopathy (CAR) and melanoma-associated retinopathy (MAR). However, our understanding of the

\footnotetext{
* Correspondence: adamusg@ohsu.edu

'Ocular Immunology Laboratory, Oregon Health and Science University, 3181 SW Sam Jackson Pk Rd, Portland, OR 97239, USA

Full list of author information is available at the end of the article
}

pathogenicity of autoimmune retinopathies is still incomplete. Evidence suggests that autoantibodies (AAbs) specific to distinct retinal antigens are present in sera from patients with AR. AR affects middle age people over 50 years old and is characterized by the sudden onset and progressive loss of vision, photopsia, visual field loss, and abnormal ERG findings [1]. AR occurs in some patients who are also predisposed to autoimmune diseases or have family history of autoimmune diseases [2]. Studies suggest that progression of retinal degeneration over time could result from the attack by the immune system on healthy retina [3-5].

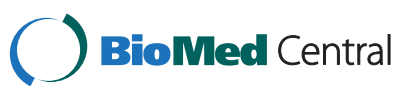


As in other autoimmune disorders, AR including CAR is characterized by the presence of a diverse serum autoantibody repertoire, but not all target antigens have been identified [1,6]. Moreover, heterogeneity in anti-retinal autoantibody recognition may produce distinctive retinal disorders [4,7-9]. In fact, the profiling of AAbs led to valuable data aiding clinical diagnosis and prognosis of retinal dysfunction in AR; for instance, anti-recoverin AAbs are associated with severe retinal dysfunction of rods and cones whereas anti-enolase AAbs are associated with slow progressive dysfunction mostly in cones $[7,8]$. Anti-transducin phenotype is also characterized by defects in visual fields and reduced scotopic ERG responses [9]. It is also important to point out that in CAR, retinal dysfunction and AAbs may manifest months or years prior to the onset and diagnosis of cancer, thus could also be useful biomarkers for this disease [1]. Anti-retinal antibodies persist in the circulation and their levels fluctuate over long periods after the onset of visual symptoms $[6,10]$. We believe that identification of new AAbs will help to elucidate the pathophysiology in $\mathrm{AR}$, and ultimately facilitate novel immune treatments, such as antigen-tolerating therapy. In this study, we identified heat shock protein 60 (hsp60) and collapsin response mediator protein 2 (CRMP2) as possible autoantigens frequently observed in patients with CAR, MAR and AR. Anti-Hsp60 autoantibodies that often co-existed with other anti-retinal AAbs, including antirecoverin and anti- $\alpha$-enolase, may contribute to the autoimmune pathology in AR.

\section{Methods}

Patient sera

Patients' sera were acquired form the Serum Repository of Oregon Health \& Science University (OHSU). The studies were approved by the OHSU Institutional Review Board and our research adhered to the tenets of the Declaration of Helsinki. The subjects presented unexplained, progressive visual loss, night vision loss, defects in visual field -paracentral or central scotoma, abnormal ERG, and had either cancer or the suspicion of cancer. We retrospectively evaluated 1260 retinopathy patients' western blotting data and identified 237 patients with AAbs against retinal proteins of an apparent molecular range of $60-70-\mathrm{kDa}$.

\section{Western blotting}

Human retinal proteins were extracted from a donor retina with $2 \%$ octyl glucoside in phosphate buffer ( $\mathrm{pH} 7.2)$ and $10 \mu \mathrm{g}$ of protein per lane was separated by SDS-gel electrophoresis using 10\% Bio-Rad Criterion gels (Hercules, CA, USA) followed by transfer to a PVDF membrane as described before [6]. After two-dimensional (2-D) gel electrophoresis (see below) retinal proteins were also transferred to the PVDF membrane. Blots were then immunostained with 1:25 diluted patient sera followed by incubation with anti-human IgG ( $\mathrm{H}$ and $\mathrm{L}$ chain) conjugated to alkaline phosphatase (Invitrogen, Grand Island, NY, USA). The immune reaction was then developed using AP substrate (Invitrogen). As positive controls in 1-D blots, we used a reference human serum containing anti-enolase AAbs at 1:100, anti-enolase Enol-1 MAb at 1:2000, and anti-recoverin R2 antiserum at 1:50,000 dilutions (both antibodies were developed in our laboratory). A negative control contained secondary antibodies only.

For verification experiments we used purified human recombinant $\mathrm{Hsp} 60$ and recombinant M. bovis Hsp65 (native) protein purchased from StressMarq Bioscience (Victoria, BC, Canada), and the appropriate secondary antibodies against human Hsp60, Hsp65, and Hsp70 from Cell Signaling Technology (Danvers, MA, U.S.A.). Collapsin response mediator protein 2 (CRMP-2; Kinasource, UK) was used for western blots using the control sheep anti-human CRMP-2 antibodies form Kinasource, UK.

\section{Immunomics - a library of $60-70-k D a$ retinal antigens}

This methodology was to identify retinal proteins reactive with patient AAbs within a $60-70-\mathrm{kDa}$ molecular range and consisted of 3 essential steps: (i) the preparation of retinal protein extracts, (ii) the screening of autoantigens by Western blotting, and (iii) the identification of the relevant proteins from the gel using mass spectrometry. The identification of protein antigens was performed as follows: $30 \mu \mathrm{g}$ of human retinal proteins were separated by SDS-PAGE and then stained with Coomassie brilliant blue. The slabs of $1 \mathrm{D}$-gels within the desired molecular weight range $(60-70-\mathrm{kDa})$ were cut into 1-mm pieces, and subjected to in-gel trypsin digestion as previously described [11]. Protein identification was performed by liquid chromatography-tandem mass spectrometry (LC-MS/MS) of peptides using Agilent 1100 series capillary LC system, $140 \mathrm{~min}$ long acetonitrile gradient and reverse phase column, and data-dependent MS/MS scans using an LTQ linear ion trap mass spectrometer (Thermo Scientific, San Jose, CA) [11]. The resulting MS/MS spectra were matched to theoretical fragmentation spectra of peptides generated from a human-only version of the Swiss-Prot database (Swiss Institute of Bioinformatics, Geneva, Switzerland) containing 19042 entries using Sequest (version 27, rev. 12, Thermo Scientific). A static mass shift of 57 was added to all cysteine residues to account for carbamidomethylation, and a differential mass shift of 16 was applied to methionine residues to detect possible oxidation. Parent and fragment ion tolerances of 3 and $1 \mathrm{Da}$ were used, respectively, and no enzyme specificity was used during the search. The 
program Scaffold (version 3.6.5, Proteome Software Inc., Portland, OR) was used to validate MS/MS-based peptide and protein identifications. Minimum peptide and protein identification probabilities of 80 and $99 \%$ were required respectively, and a minimum of at least 2 unique peptide assignments to each identified protein.

\section{Two-dimensional gel electrophoresis and mass spectrometry}

Human retinal extracts were desalted and $150 \mu \mathrm{g}$ of proteins were loaded onto a rehydrated IPG strip $(11 \mathrm{~cm})$ overnight using $\mathrm{pH}$ range 5-8. The isoelectrofocusing was run at 30,000 volt hours and then the strips were stored at $-80^{\circ} \mathrm{C}$ until use. The second dimension electrophoresis was run using 10\% Bio-Rad Criterion gels in Tris-Glycine buffer, pH 8.3 at $150 \mathrm{~V}$ for $1 \mathrm{hr}$. The gels were stained in colloidal Coomassie Blue G250 and photographed, or transferred to a PVDF membrane for western blotting analysis. Protein spots were excised from the gel based on the antibody reactivity with antigens on 2-D blots and then identified by mass spectrometry as described above.

\section{Quantitative ELISA}

Specific tests for determination of human Hsp60 proteins and anti-Hsp60 antibodies in serum were performed using commercial kits from Enzo Life Sciences (Plymouth, PA) following the manufacture's procedures. We quantified circulating Hsp60 in 1:500 diluted sera from $20 \mathrm{AR}$ patients and 20 normal patients in duplicate using a quantitative sandwich immunoassay. The second assay quantified of anti-Hsp60 antibodies in 1:500 diluted sera of 27 control patients and 46 AR patients. The color reaction was measured at $450 \mathrm{~nm}$ using a Bio-Rad Microplate Reader. Statistical analysis was performed with GraphPad Prism software (GraphPad Software, Inc. San Diego, CA) using a two-tailed Man Whitney $t$ test. Differences with a $\mathrm{p}$ value $<0.05$ were considered significant and are denoted by an asterisk.

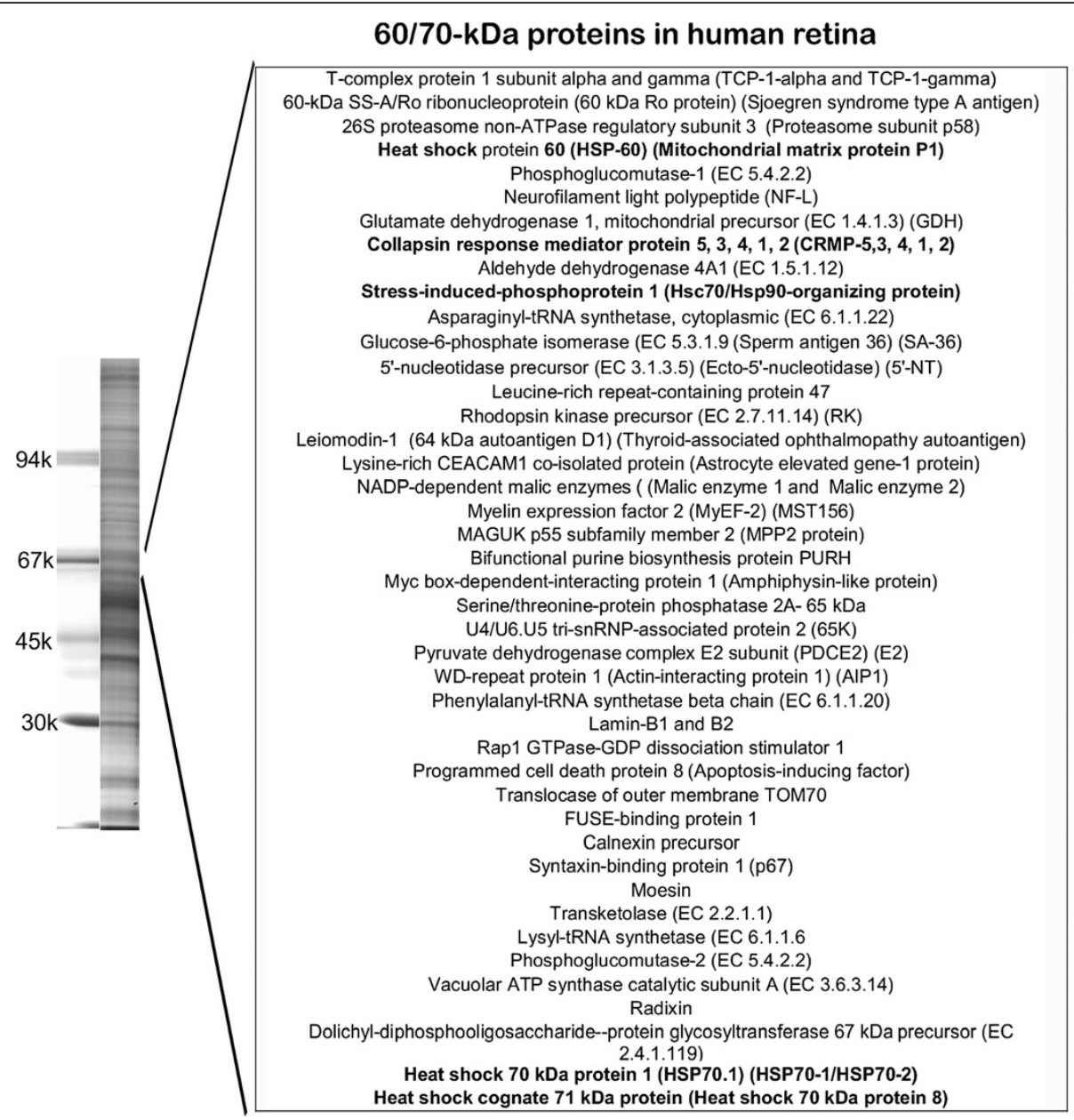

Figure 1 Human retinal proteins found in the 1-D gel within the molecular weight 60 to $70-k D a$ range. Proteins were identified using in-gel digestion and mass spectrometry (see Methods). On the left, a picture representing a separation of human retinal proteins on $10 \%$ gel. 


\section{Results}

We observed a diverse retinal antigen recognition pattern by human AAbs as tested by Western blotting and not all retinal proteins targeted by AAbs have been identified at the molecular level. Retrospective evaluation of 1260 sera from patients with ocular symptoms of AR tested for anti-retinal AAbs revealed 819 seropositive samples. Based on western blot analysis, about $29 \%$ of those seropositive patients had AAbs that targeted retinal proteins at a molecular range from $60-70-\mathrm{kDa}$ presenting as single specificity AAbs in the serum or coexisted with other antibodies, including anti-recoverin or anti-enolase in those patients. In contrast, $15 \%$ of control subjects had AAbs reacting with 60-70-kDa retinal proteins. Proportionally, AAbs against a $\sim 62-\mathrm{kDa}$ protein were more common than against a $70-\mathrm{kDa}$ protein. To identify potential retinal autoantigens, we first identified all major retinal proteins present in the 60-70 kDa range on a 1-D SDS-PAGE gel using in-gel digestion and mass spectrometry. This procedure identified 66 human retinal proteins within the desired molecular range (Figure 1) as candidate antigenic targets. Among the proteins from the gel we found a group of heat shock proteins (hsps), including heat shock protein 60 (CH60_HUMAN), heat shock $70 \mathrm{kDa}$ protein 1A/1B (HSP71_HUMAN), heat shock $70 \mathrm{kDa}$ protein 12A (HS12A_HUMAN), and heat shock cognate $71 \mathrm{kDa}$ protein (HSP7C_HUMAN).

Recognizing that one band on the 1-D gel often represents more than one protein we further focused on the identification of immunoreactive proteins by 2-DWestern blotting based on the autoantibody recognition pattern for 10 randomly selected sera that previously have shown binding to a $\sim 62-\mathrm{kDa}$ protein. Figure $2 \mathrm{~A}$ shows immunoblots for 10 serum autoantibodies that bind to different retinal proteins within the molecular range of 60 to $70-\mathrm{kDa}$ (boxed). These 10 sera were selected to be further analyzed by 2-D western blotting (shown in Figure 3). Specific anti-hsp60 and hsp70 were used as positive controls and no primary antibodies as a negative control. Figure $2 \mathrm{~B}$ shows a representative 2-D western blot for serum\#3 (Figure 2A) immunoreacting with 3 molecular forms of $62-\mathrm{kDa}$ protein. Figure 4 shows a representative Coomassie blue stained gel with 17 marked proteins of interest located at the 60 to $70-\mathrm{kDa}$ range and the $\mathrm{p} I$ range of 5.5 to 6.5 and immunoreacting with patients' sera. Based on immunoreactivity with sera the reactive spots were excised from 2-D gel and identified by in-gel digestion and mass spectrometry. Table 1 present 17 successfully identified spots that belonged to the stress protein family, including mitochondrial heat shock protein $60-\mathrm{kDa}$, heat shock $70-\mathrm{kDa}$ protein 1 , heat shock cognate $71-\mathrm{kDa}$ protein, heat shock $70-\mathrm{kDa}$ protein $1 \mathrm{~L}$, mitochondrial stress-70

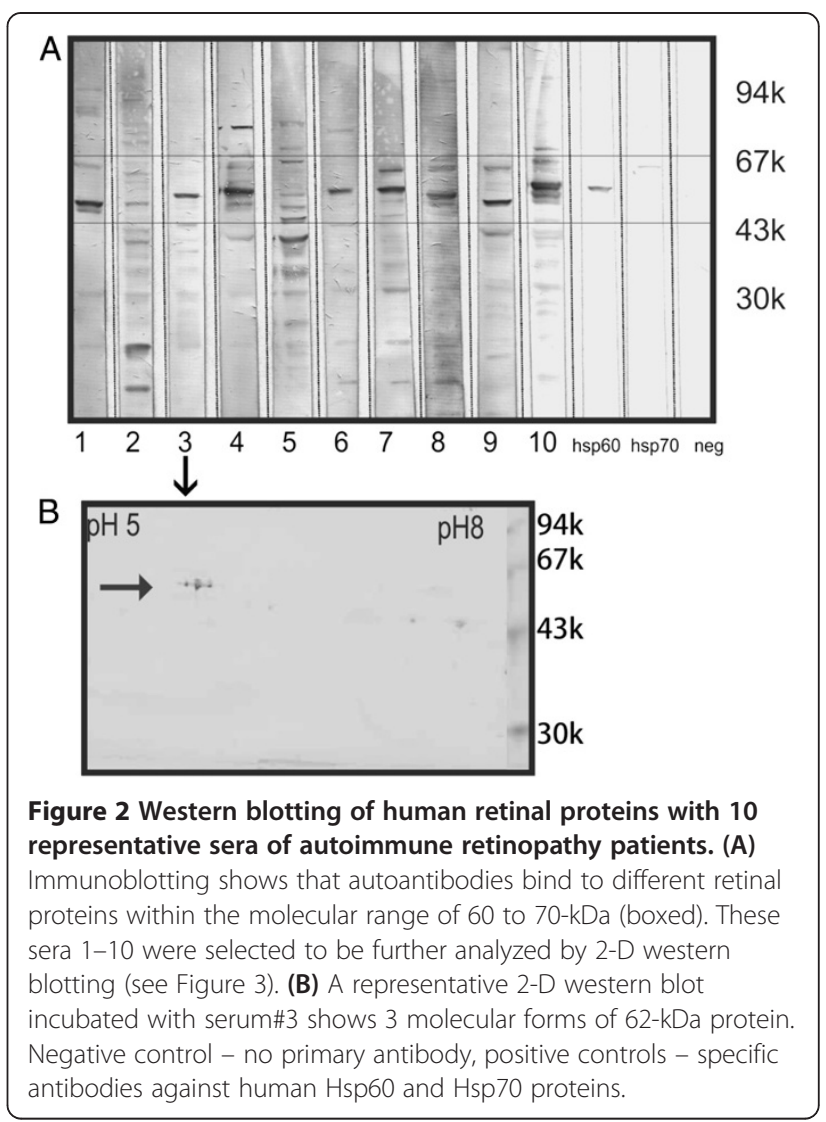

protein, heat shock-related $70-\mathrm{kDa}$ protein 2 , and spots related to collapsin response mediator proteins (CRMPs; dihydropyrimidinase-related proteins), including CRMP2 (DPYL2_HUMAN) and CRMP-3 (DPYL3_HUMAN). Multiple isoforms visible on the gel of these 6 heat shock proteins and two CRMP proteins could be caused by post-translational modifications. Two-D western blots using 8 of the 10 sera (presented in Figure 2) were used to localize which of the proteins in the $60-70 \mathrm{kDa}$ and pI 5-6.5 range were potentially immunoreactive (Figure 3B-I). Among heat shock proteins, the mitochondrial $60-\mathrm{kDa}$ hsp was most often recognized by AAbs. Similarly, immunoreactive spots migrated in similar positions to CRMP-2/3. The presence of multiple CRMP spots with the same molecular weight is not surprising since CRMPs are highly phosphorylated proteins [12].

CRMPs are a family of neuronal cytoplasmic proteins present in adult central and peripheral neurons and they define axon/dendrite fate and axonal growth of neurons through protein-protein interactions. They are also present in cancer cells, including small cell lung carcinomas and AAbs against CRMP-2 [13], CRMP-5 [14], and CRMP-3-4 [15] were reported in association with cancer. Remarkably, our CAR 


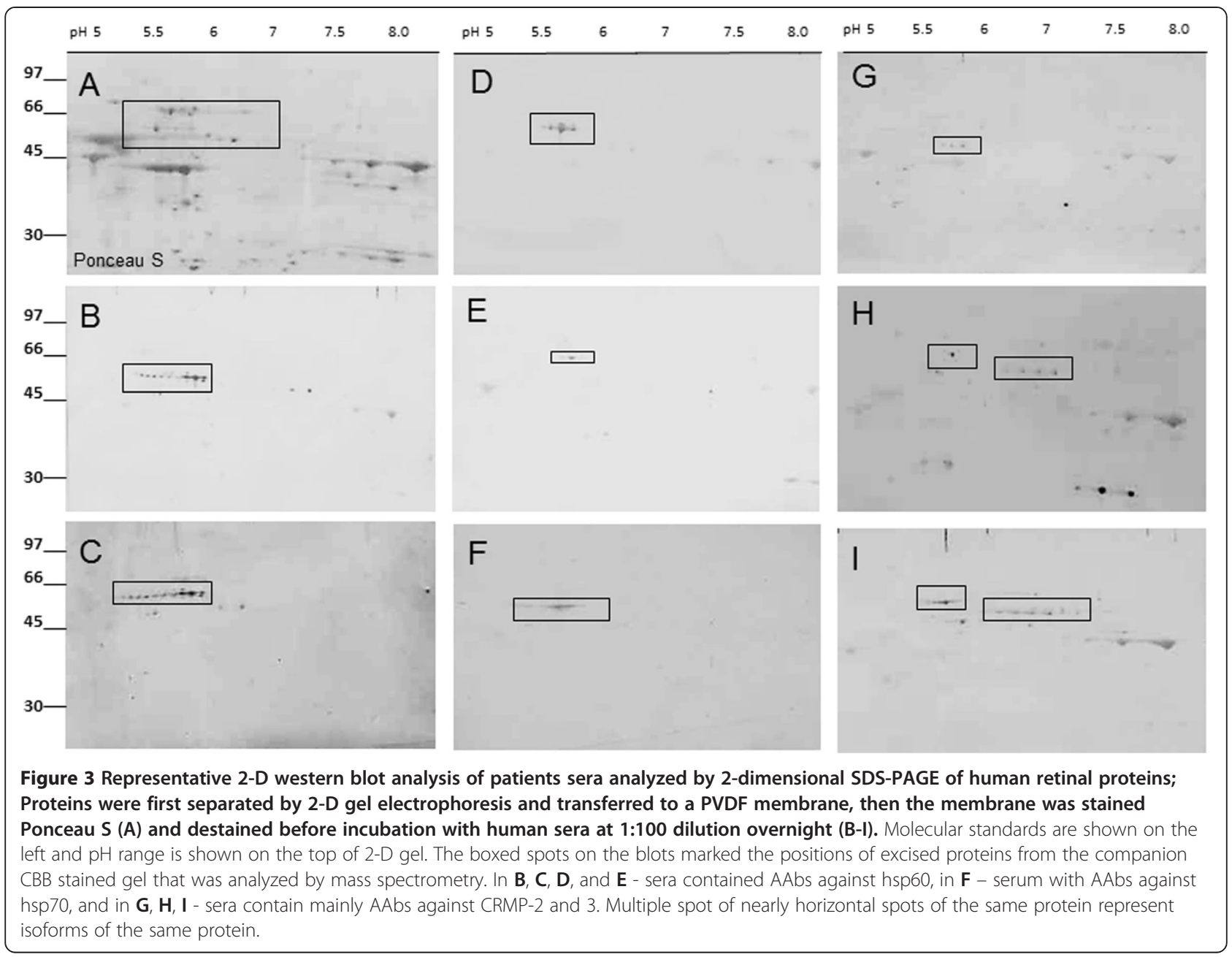

patients with anti-CRMP-2 AAbs were diagnosed with melanoma, breast cancer, and lymphoma (Figure 3G, H, I).

The results were validated for 15 sera by $1-\mathrm{D}$ western blotting (Figure 5) using purified $60-\mathrm{kDa}$ and $65-\mathrm{kDa}$ heat shock proteins and CRMP-2 protein. Figure 5C demonstrated that sera were binding to different isoforms of CRMP-2. Unfortunately other purified CRMP proteins are not available for testing. Since the purified recombinant CRMP-2 preparation contained several lower molecular weight bands that were also immunoreactive, the results suggested that some AAbs bound more tightly to truncated forms of CRMP-2. The immunoreactivity of many of the sera with purified hsp60, hsp65, and CRMP-2 provided additional evidence supporting the putative identifications of hsp60 and CRMP-2 as immunoreactive proteins on the 2-D western blots.

Next, we investigated the level of hsp60 and antihsp60 antibodies in the serum of AR patients and healthy subject controls. Elevated levels of hsp60 were associated with stress and cancer, e.g. colorectal cancer patients [16,17]. Hsp60 is mainly located in the mitochondria but can change its location to the cytosol and cell surface and then becomes available [18]. We performed 2 quantitative assays; initially, we examined the level of circulating hsp60 in the serum and then we determined serum anti-hsp60 antibody levels. The quantification of hsp60 in 20 AR patients and 20 healthy individuals sera showed the mean concentration hsp60 of $49.6 \pm 9 \mathrm{ng} \cdot \mathrm{mL}^{-1}$ in control sera and $38.8 \pm 10 \mathrm{ng} \cdot \mathrm{mL}^{-1}$ in AR sera; however, there was no statistical difference between groups in serum hsp60 levels (Figure 6A). In contrast, there was a significant difference in serum $\mathrm{AAb}$ levels between control, $\mathrm{AR}$ and CAR groups. Figure $6 \mathrm{~B}$ shows the total serum IgG/A/M against human hsp60 in 14 CAR patients, 32 AR patients, and 27 healthy subjects. There were significantly elevated levels of anti-hsp60 AAbs in CAR $\left(2.24 \pm 0.13 \mathrm{ng} \cdot \mathrm{mL}^{-1}\right)$ and AR sera $\left(2.15 \pm 0.10 \mathrm{ng} \cdot \mathrm{mL}^{-1}\right)$ compared to healthy subjects $\left(1.56 \pm 0.06 \mathrm{ng} \cdot \mathrm{mL}^{-1}\right.$; One-way ANOVA, $\mathrm{p}<0.0001$ ), suggesting these antibodies can be a biomarker for autoimmune retinopathy. 


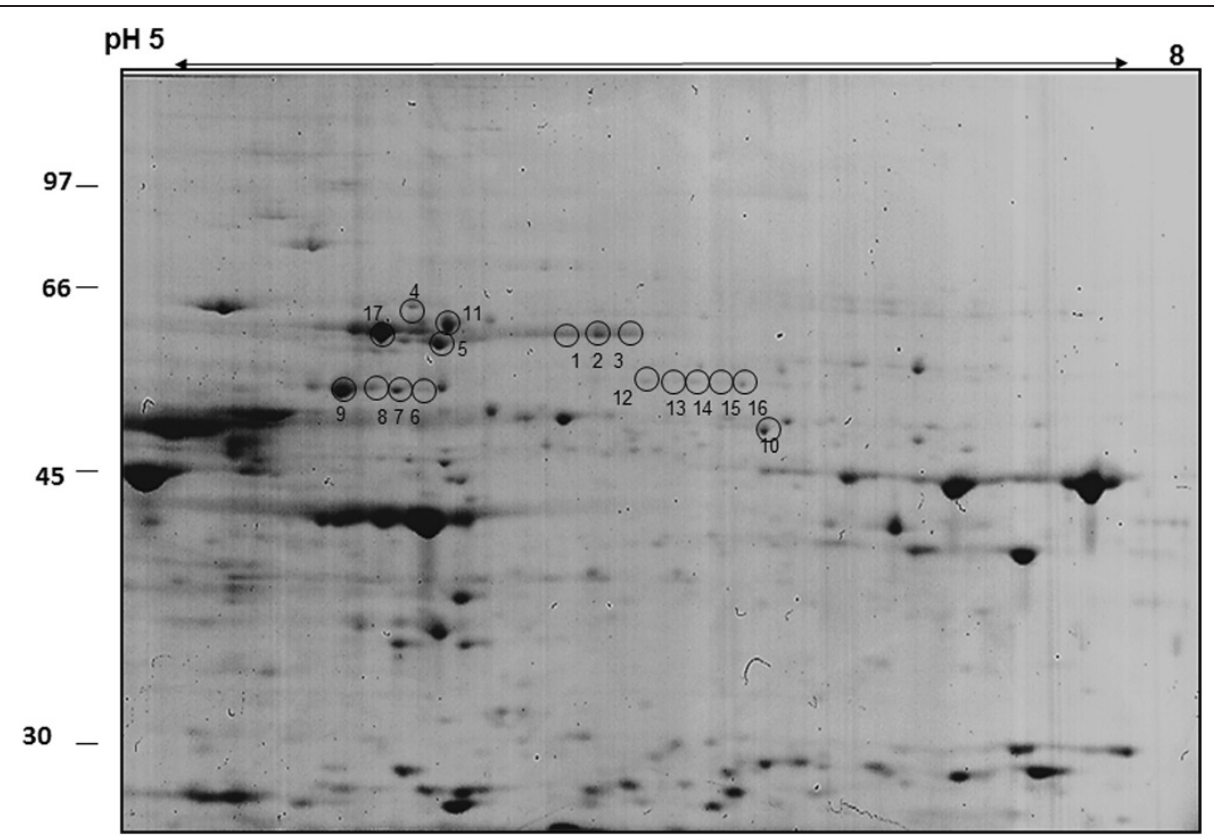

Figure 4 Representative proteome profile of human retinal proteins separated by 2-D gel electrophoresis in the pH range 5-8 and stained with Coomassie Brilliant blue. Molecular weight of standards is shown on the left and pH range on the top. Circles with numbers indicate the excised protein spots identified as heat shock proteins (HSP) or collapsin response mediator proteins (CRMP). The identified proteins are listed in Table 1.

\section{Discussion}

Anti-retinal autoantibodies of different specificities have been liked to AR and CAR. Our studies identified often targeted retinal proteins in the range $60-70-\mathrm{kDa}$ as putative heat shock proteins and CRMP proteins and these specific AAbs were present alone or in association with other antibodies. It is not undetermined why patients with retinopathy possess AAbs that targeted hsps. Although the role of anti-hsp antibodies in retinopathy is unknown experimental findings from animal studies support their pathogenic role. The hsp70 family of proteins is best known among chaperon proteins for protection against stress-induced protein degeneration $[19,20]$. Blocking the function of hsps by specific AAbs is likely to remove protective effects of such proteins in the cell. Ohguro et al. showed serum AAbs against recoverin and heat shock cognate protein 70 (hsc70) concurrently present in four Japanese CAR patients, suggesting that anti-hsc70 AAbs might intensified pathogenic effects of anti-recoverin AAbs on the retina during the autoimmune process [21]. In our patient's cohort, 37 out of 819 sera revealed anti-recoverin AAbs, and among them, about $30 \%$ anti-recoverin-positive sera had additional AAbs against $60-70-\mathrm{kDa}$ retinal proteins. Out of 15 CAR patients with anti-recoverin AAbs eight had lung cancer but only three of those patients had additional anti-67$\mathrm{kDa}$ AAbs. Because such a low incidence of co-existence of anti-recoverin/anti-67-kDa in our cohort of Caucasian patients we speculated, that perhaps, the generation of
anti-67-kDa antibody is genetically restricted and the ethnic background may predispose individuals to the generation of such AAbs. More patients of different ethnicity must be examined to determine whether this hypothesis holds up.

Also, AAbs against a 70-kDa hsp were found in serum of patients with glaucoma and were increased in aqueous humor of those patients compared with the non-glaucoma group, which supports an autoimmune involvement in the pathogenic process in glaucoma [22]. Furthermore, immunization of Lewis rats with hsp27 and hsp60 induced the retinal ganglion cell degeneration and axonal loss in a pattern similar to human glaucoma, including topographic cell loss in this glaucoma rat model [23]. In animal studies of CAR in Lewis rats, the CAR-like retinal dysfunction was more pronounced when anti-recoverin antibodies were co-administrated with antibodies against hsp70 by intravitreal injection [21]. Therefore, it is possible that in susceptible patients, autoimmunity to hsp plays a role in augmenting the effects of coexisting pathogenic AAbs against other retinal proteins, such as recoverin or $\alpha$-enolase.

Hsp60 is an immunodominant antigenic component of different common pathogens, thus there is a consensus that hsp60-specific antibodies may be developed in response to infections as a defense mechanism against pathogens. In fact, our patients AAbs bound better to hsp65, which is a microbial form of hsp60 (Figure 5). A 
Table 1 Identification of human retinal proteins found in spots cut out of a Coomassie-stained 2D gel by mass spectrometry

\begin{tabular}{|c|c|c|c|}
\hline Spot number & Major protein(s) & Accession & Spectral counts \\
\hline 1 & Heat shock cognate $71 \mathrm{kDa}$ protein & HSP7C_HUMAN & 89 \\
\hline \multirow{2}{*}{2} & Heat shock cognate $71 \mathrm{kDa}$ protein & HSP7C_HUMAN & 59 \\
\hline & Heat shock $70 \mathrm{kDa}$ protein $1 \mathrm{~A} / 1 \mathrm{~B}$ & HSP71_HUMAN & 30 \\
\hline \multirow{2}{*}{3} & Stress-70 protein, mitochondrial & GRP75_HUMAN & 29 \\
\hline & Heat shock cognate $71 \mathrm{kDa}$ protein & HSP7C_HUMAN & 22 \\
\hline \multirow{3}{*}{4} & Heat shock cognate $71 \mathrm{kDa}$ protein & HSP7C_HUMAN & 14 \\
\hline & $60 \mathrm{kDa}$ heat shock protein, mitochondrial & CH60_HUMAN & 8 \\
\hline & Alpha-internexin & AINX_HUMAN & 10 \\
\hline \multirow[t]{2}{*}{5} & Vimentin & VIME_HUMAN & 7 \\
\hline & Dihydropyrimidinase-related protein 2 & DPYL2_HUMAN & 6 \\
\hline \multirow[t]{2}{*}{6} & $60 \mathrm{kDa}$ heat shock protein, mitochondrial & CH60_HUMAN & 40 \\
\hline & $60 \mathrm{kDa}$ heat shock protein, mitochondrial & NUCB1_HUMAN & 18 \\
\hline \multirow[t]{4}{*}{7} & Alpha-internexin & AINX_HUMAN & 11 \\
\hline & Pyruvate kinase isozymes M1/M2 & KPYM_HUMAN & 8 \\
\hline & Nucleobindin-1 & NUCB1_HUMAN & 11 \\
\hline & Alpha-internexin & AINX_HUMAN & 10 \\
\hline \multirow{5}{*}{8} & Alpha-1-antitrypsin & A1AT_HUMAN & 8 \\
\hline & Rab GDP dissociation inhibitor alpha & GDIA_HUMAN & 7 \\
\hline & Protein kinase $\mathrm{C}$ and casein kinase & PACN1_HUMAN & 6 \\
\hline & substrate in neurons protein 1 & & \\
\hline & Rab GDP dissociation inhibitor alpha & GDIA_HUMAN & 8 \\
\hline \multirow{3}{*}{9} & Nucleobindin-1 & NUCB1_HUMAN & 7 \\
\hline & Pyruvate kinase isozymes M1/M2 & KPYM_HUMAN & 6 \\
\hline & Alpha-1-antitrypsin & A1AT_HUMAN & 5 \\
\hline 10 & Succinyl-CoA:3-ketoacid coenzyme A transferase 1 & SCOT1_HUMAN & 17 \\
\hline 11 & Stress-70 protein, mitochondrial & GRP75_HUMAN & 81 \\
\hline 12 & Dihydropyrimidinase-related protein 2 & DPYL2_HUMAN & 57 \\
\hline 13 & Dihydropyrimidinase-related protein 3 & DPYL3_HUMAN & 28 \\
\hline 14 & Dihydropyrimidinase-related protein 3 & DPYL3_HUMAN & 21 \\
\hline 15 & Dihydropyrimidinase-related protein 3 & DPYL3_HUMAN & 20 \\
\hline 16 & Dihydropyrimidinase-related protein 3 & DPYL3_HUMAN & 14 \\
\hline 17 & $60 \mathrm{kDa}$ heat shock protein, mitochondrial & CH60_HUMAN & 60 \\
\hline
\end{tabular}

Spots were cut out of a Coomassie-stained 2D gel of human retinal proteins in a molecular weight range from approximately 60-70 kDa and pl of 5.0-6.5 and subjected to in-gel digestion with trypsin. See Figure 3 for spot numbers.

high degree of antigenic homology (47\%) between microbial (bacterial and parasitic) and human hsp60 could possibly cause infection-induced autoimmunity [20]. The homology between bacterial and human hsp could also explain the presence of these AAbs in the serum of healthy individuals [24,25]. Therefore, anti-hsp60 antibodies in the serum of healthy individuals may represent the natural autoantibody repertoire, whose formation might be in response to common infections acquired throughout life. Molecular mimicry has been suggested as a mechanism for the formation of AAbs and autoreactive $\mathrm{T}$ cells against hsp that were upregulated during stress [26]. Moreover, hsp also share homology with retinal proteins, such as IRBP which could amplify pathogenicity of anti-retinal AAbs/T cells throughout the disease process $[27,28]$. Taken together, the increased levels of anti-hsp AAbs in patients with AR suggests that elevated anti-hsp immune responses may have a contributory role in autoimmune retinal degeneration and needs to be further investigated. 

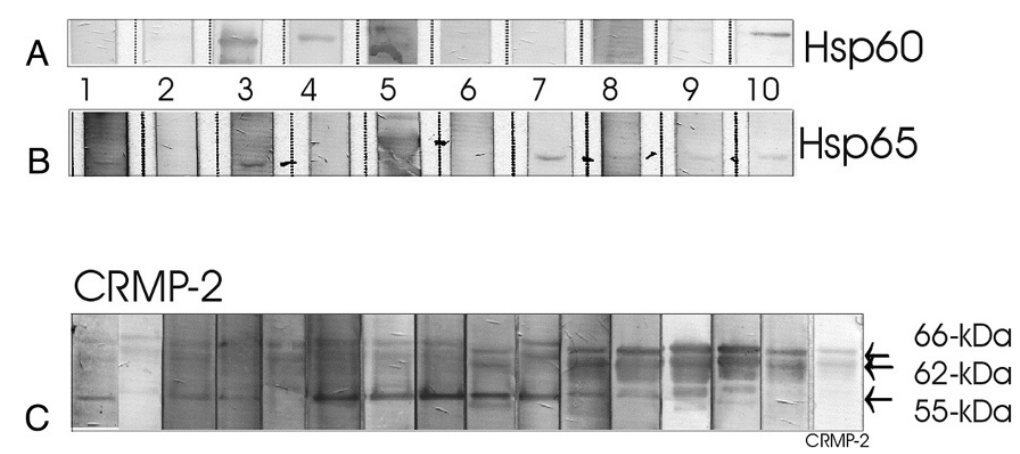

Figure 5 Confirmation western blotting using purified proteins for representative patients' sera. Two hsp60s were used with sera presented in Figure 2. (A) Recombinant human hsp60 and (B) recombinant M. bovis Hsp65 (native) proteins (member of the hsp60 family of heat shock proteins); Note that some AAbs recognized only hsp65. (C) Recombinant CRMP-2 incubated with 15 patients' sera that were suspected to react with CRMP-2. Patients' AAbs bound to different molecular forms of CRMP-2, suggesting they recognized different epitopes. We used specific anti-human antibodies against CRMP-2 as positive control.

CRMP-1-4 exhibit 68-75\% sequence identity with one another but the sequence composition of CRMP5 differs significantly from CRMP-1-4 and shows only about 50\% homology [29]. To verify the reactivity with CRMP-2 we used human recombinant CRMP-2 protein on the blot. Figure $3 \mathrm{C}$ shows 15 serum samples that recognized different CRMP-2 molecular forms. The 64- and $66-\mathrm{kDa}$ bands of CRMP-2 are two phosphorylated isoforms of 62-kDa CRMP-2 [30] and both isoforms were recognized by AAbs on the blots. Moreover, seven sera strongly bound to the 55$\mathrm{kDa}$ breakdown product (BDP) of CRMP-2 [31,32], suggesting that these AAbs recognized different fine epitopes on the protein. AAbs against CRMP 2 and 3 have not been described in retinopathy before so they could be considered as novel biomarkers for the disease and their pathogenic properties will be further investigated.

\section{Conclusion}

In conclusion, different anti-retinal antibodies frequently co-exist in a single patient, creating antibody-arrays related to the syndrome. We believe that prompt identification of antigenic targets may lead to better diagnosis of AR and associated cancer and understating the causative role of AAbs in retinal pathology. Anti-hsp60 AAbs could be initiated in response to microbial and oncological antigens that also cross-react with antigens in the retina. Because of the frequent association of anti-hsp antibodies with other anti-retinal antibodies in the same patient, it is possible that they augment the pathogenic effects on the retina, leading to cell death and retinal degeneration. An additional research is also needed to investigate the relationship between circulating anti-hsp60 in the progression of AR. Regardless of their role in development of AR these AAbs can serve as useful clinical predictors of autoimmune retinal degeneration.
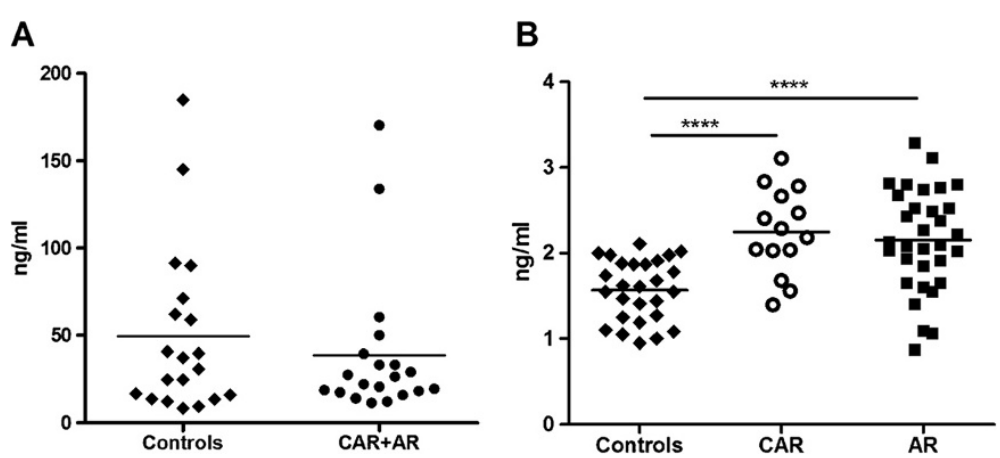

Figure 6 Quantification of serum hsp60 and anti-hsp60 antibodies in patients with cancer associated retinopathy (CAR), autoimmune retinopathy (AR), and healthy subjects as controls. (A) Levels of circulating serum hsp60 in 20 AR patients and 20 controls; the mean concentration of hsp60 $49.6 \pm 9 \mathrm{ng} \cdot \mathrm{mL}^{-1}$ in control sera and $38.8 \pm 10 \mathrm{ng} \cdot \mathrm{mL}^{-1}$ in AR sera; (B) Serum levels of human anti-hsp60 lgG/A/M in the cohort of 27 controls, 14 CAR, and 32 AR patients were measured by ELISA; Anti-hsp60 AAbs were significantly elevated levels of in CAR (2.24 \pm 0.13 $\left.\mathrm{ng} \cdot \mathrm{mL}^{-1}\right)$ and AR sera $\left(2.15 \pm 0.10 \mathrm{ng} \cdot \mathrm{mL}^{-1}\right)$ compared to healthy subjects $\left(1.56 \pm 0.06 \mathrm{ng} \cdot \mathrm{mL}^{-1}\right.$; One-way ANOVA, $\left.\mathrm{p}<0.0001\right)$. The line represents the mean level for tested groups in $\mathbf{A}$ and $\mathbf{B}$. 


\section{Competing interests}

The authors declare that they have no competing interests.

\section{Authors' contributions}

All authors made contribution to the manuscript. GA contributed to the study conception and design, providing funding for materials, interpreting data, drafting and critically revised the manuscript. LD contributed to design, providing funding for materials, interpreting data, and critically revised the manuscript. RB and LB designed and preformed experiments, collected and analyzed data. All authors read and approved the final manuscript.

\section{Acknowledgments}

This work was supported by the National Eye Institute Grants EY13053 (GA) and EY10572 (LD) and unrestricted grant to Casey Eye Institute from the Foundation to Prevent Blindness.

\section{Author details}

'Ocular Immunology Laboratory, Oregon Health and Science University, 3181 SW Sam Jackson Pk Rd, Portland, OR 97239, USA. ${ }^{2}$ Casey Eye Institute, and Department of Biochemistry \& Molecular Biology, Oregon Health and Science University, Portland, OR, USA. ${ }^{3}$ Current address: Oregon Stem Cell Center, Oregon Health and Science University, 3181 SW Sam Jackson Pk Rd, Portland, OR 97239, USA.

Received: 10 July 2013 Accepted: 6 September 2013 Published: 25 September 2013

\section{References}

1. Adamus G: Autoantibody targets and their cancer relationship in the pathogenicity of paraneoplastic retinopathy. Autoimmun Rev 2009, 8(5):410-414.

2. Heckenlively J, Ferreyra H: Autoimmune retinopathy: a review and summary. Sem Immunopathol 2008, 30(2):127-134.

3. Adamus G: Autoantibody-induced apoptosis as a possible mechanism of autoimmune retinopathy. Autoimmun Rev 2003, 2:63-69.

4. Mantel I, Ramchand KV, Holder GE, Ohbayashi M, Morohoshi K, Patel N, Toda M, Fitzke FW, Bird AC, Ono SJ: Macular and retinal dysfunction of unknown origin in adults with normal fundi: evidence for an autoimmune pathophysiology. Exp Mol Pathol 2008, 84(2):90-101.

5. Kyger M, Worley A, Adamus G: Autoimmune responses against photoreceptor antigens during retinal degeneration and their role in macrophage recruitment into retinas of RCS rats. J Neuroimmunol 2013, 254(1-2):91-100.

6. Adamus G, Ren G, Weleber RG: Autoantibodies against retinal proteins in paraneoplastic and autoimmune retinopathy. BMC Ophthalmol 2004, 4(1):5.

7. Ohguro H, Yokoi Y, Ohguro I, Mamiya K, Ishikawa F, Yamazaki H, Metoki T, Takano Y, Ito T, Nakazawa M: Clinical and immunologic aspects of cancerassociated retinopathy. Amer J Ophthalmol 2004, 137(6):1117-1119.

8. Weleber RG, Watzke RC, Shults WT, Trzupek KM, Heckenlively JR, Egan RA, Adamus G: Clinical and electrophysiologic characterization of paraneoplastic and autoimmune retinopathies associated with antienolase antibodies. Am J Ophthalmol 2005, 139(5):780-794.

9. Adamus G, Brown L, Weleber RG: Molecular biomarkers for autoimmune retinopathies: significance of anti-transducin-alpha autoantibodies. Exp Mol Pathol 2009, 87(3):195-203.

10. Saito W, Kase S, Ohguro H, Furudate N, Ohno S: Slowly progressive cancerassociated retinopathy. Arch Ophthalmol 2007, 125(10):1431-1433.

11. Shin JB, Longo-Guess CM, Gagnon LH, Saylor KW, Dumont RA, Spinelli KJ, Pagana JM, Wilmarth PA, David LL, Gillespie PG, et al: The R109H variant of fascin-2, a developmentally regulated actin crosslinker in hair-cell stereocilia, underlies early-onset hearing loss of DBA/2J mice. J Neurosci 2010, 30(29):9683-9694.

12. Arimura N, Inagaki N, Chihara K, Menager C, Nakamura N, Amano M, Iwamatsu A, Goshima Y, Kaibuchi K: Phosphorylation of collapsin response mediator protein-2 by Rho-kinase. Evidence for two separate signaling pathways for growth cone collapse. J Biol Chem 2000, 275(31):23973-23980.

13. Wu CC, Chen HC, Chen SJ, Liu HP, Hsieh YY, Yu CJ, Tang R, Hsieh LL, Yu JS, Chang YS: Identification of collapsin response mediator protein-2 as a potential marker of colorectal carcinoma by comparative analysis of cancer cell secretomes. Proteomics 2008, 8(2):316-332.
14. Monstad S, Drivsholm L, Skeie G, Aarseth J, Vedeler C: CRMP5 antibodies in patients with small-cell lung cancer or thymoma. Cancer Immunol Immunother 2008, 57(2):227-232.

15. Knudsen A, Bredholt G, Storstein A, Oltedal L, Davanger S, Krossnes B, Honnorat J, Vedeler CA: Antibodies to CRMP3-4 associated with limbic encephalitis and thymoma. Clin Exp Immunol 2007, 149(1):16-22.

16. Lewthwaite J, Owen N, Coates A, Henderson B, Steptoe A: Circulating human heat shock protein 60 in the plasma of British civil servants: relationship to physiological and psychosocial stress. Circulation 2002, 106(2):196-201.

17. Hamelin C, Cornut E, Poirier F, Pons S, Beaulieu C, Charrier J-P, Haïdous H, Cotte E, Lambert C, Piard F, et al: Identification and verification of heat shock protein 60 as a potential serum marker for colorectal cancer. FEBS J 2011, 278(24):4845-4859.

18. Soltys BJ, Gupta RS: Cell surface localization of the $60 \mathrm{kDa}$ heat shock chaperonin protein (Hsp60) in mammalian cells. Cell Biol Internat 1997, 21(5):315-320.

19. Franklin TB, Krueger-Naug AM, Clarke DB, Arrigo A-P, Currie RW: The role of heat shock proteins $\mathrm{Hsp} 70$ and $\mathrm{Hsp} 27$ in cellular protection of the central nervous system. Internat J Hyperther 2005, 21(5):379-392.

20. Garrido C, Gurbuxani S, Ravagnan L, Kroemer G: Heat shock proteins: endogenous modulators of apoptotic cell death. Biochem Biophys Res Commun 2001, 286(3):433-442.

21. Ohguro H, Ogawa K, Maeda T, Maeda A, Maruyama I: Cancer-associated retinopathy induced by both anti-recoverin and anti- hsc70 antibodies in vivo. Invest Ophthalmol Vis Sci 1999, 40(13):3160-3167.

22. Joachim SC, Bruns K, Lackner KJ, Pfeiffer N, Grus FH: Antibodies to alpha $B$-crystallin, vimentin, and heat shock protein 70 in aqueous humor of patients with normal tension glaucoma and lgG antibody patterns against retinal antigen in aqueous humor. Curr Eye Res 2007, 32(6):501-509.

23. Wax MB, Tezel G, Yang J, Peng G, Patil RV, Agarwal N, Sappington RM, Calkins DJ: Induced autoimmunity to heat shock proteins elicits glaucomatous loss of retinal ganglion cell neurons via activated T-cellderived Fas-ligand. J Neurosci 2008, 28(46):12085-12096.

24. Uray K, Hudecz F, Fust G, Prohaszka Z: Comparative analysis of linear antibody epitopes on human and mycobacterial 60-kDa heat shock proteins using samples of healthy blood donors. Int Immunol 2003, 15(10):1229-1236.

25. Pashov A, Kenderov A, Kyurkchiev S, Kehayov I, Hristova S, Lacroix-Desmazes S, Giltiay N, Varamballi S, Kazatchkine MD, Kaveri SV: Autoantibodies to heat shock protein 90 in the human natural antibody repertoire. Int Immunol 2002, 14(5):453-461.

26. Oldstone MB: Molecular mimicry, microbial infection, and autoimmune disease: evolution of the concept. Curr Top Microbiol Immunol 2005, 296:1-17.

27. Rengarajan K, de Smet MD, Chader GJ, Wiggert B: Identification of heat shock proteins binding to an immunodominant uveitopathogenic peptide of IRBP. Curr Eye Res 1994, 13(4):289-296.

28. Rajaiah R, Moudgil KD: Heat-shock proteins can promote as well as regulate autoimmunity. Autoimmun Rev 2008, 8(5):388-393.

29. Fukada M, Watakabe I, Yuasa-Kawada J, Kawachi H, Kuroiwa A, Matsuda Y, Noda M: Molecular characterization of CRMP5, a novel member of the collapsin response mediator protein family. J Biol Chem 2000, 275(48):37957-37965.

30. Katano T, Tamaki M, Okuda-Ashitaka E, Inagaki N, Kinumi M, Ito S: Proteomic identification of a novel isoform of collapsin response mediator protein-2 in spinal nerves peripheral to dorsal root ganglia. Proteomics 2006, 6(22):6085-6094.

31. Zhang Z, Ottens AK, Sadasivan S, Kobeissy FH, Fang T, Hayes RL, Wang KK: Calpain-mediated collapsin response mediator protein-1, -2 , and -4 proteolysis after neurotoxic and traumatic brain injury. $J$ Neurotrauma 2007, 24(3):460-472.

32. Zhang Z, Majava V, Greffier A, Hayes RL, Kursula P, Wang KK: Collapsin response mediator protein-2 is a calmodulin-binding protein. Cell Mol Life Sci 2009, 66(3):526-536.

doi:10.1186/1471-2415-13-48

Cite this article as: Adamus et al:: Detection of autoantibodies against heat shock proteins and collapsin response mediator proteins in autoimmune retinopathy. BMC Ophthalmology 2013 13:48. 